pattern of mental handicap, with an explanation about the as yet limited predictive value of these.

The problems with predictive testing are a further example of the ethical difficulties which beset research workers. It is becoming increasingly obvious that the division between clinical and research work is not clear and that the guidelines for the research worker's responsibility to his clients need better definition.

ANTHONY KEARNS

Hospitaller Brothers of St John of God

St Mary's, Drumcar, Co Louth, Ireland

1 Daker MG, Chidiac P, Fear CN, Berg AC, Fragile X in a normal male: a cautionary tale. Lancet $1981 ; 1 ; 780$

2 Fryns JP, van den Berghe $H$. Transmission of fragile $(X)(p 27)$ from normal males. Hum Genet 1982;61:262-3.

3 Uchida IA, Joyce EM. Activity of the fragile $\mathrm{x}$ in heterozygous carriers. Am F Hum Genet 1982;34:286-93.

4 Tuckerman E, Webb T, Bundey SE. Frequency and replication status of the fragile $x$, Fra $x$ ( $27-8$ ), in a pair of monozygotic twins of markedly differing intelligence. Med Genet 1985;2 85-91.

\section{Use of molar units for drugs and toxins?}

SIR,-Professor D N Baron's leading article ( 5 July, p 2) calling for the use of trendy molar units for drugs and toxins echoes similar previous demands by clinical biochemists. ${ }^{1-3}$ Such a change would have implications reaching far beyond the narrow service involvement of clinical biochemists in therapeutic drug monitoring and emergency toxicology. It seems that little thought has been given to the much wider consequences or the adverse effects that the change would have on medical practice and the welfare of patients. Clinical chemists should recognise that many specialties other than their own are concerned with drugs and their clinical measurement, and the views of those who are responsible for the development, manufacture, marketing, prescription, administration, and investigation of drugs must be taken into account.

Apart from the inconvenience, confusion, and increased risk to patients which would result from the introduction of molar units for clinical drug measurement the clinical biochemists go further to propose seriously that drug doses should also be changed to molar units. ${ }^{145}$ This would indeed be a logical and necessary sequel if only to avoid the absurd situation which would arise if drug concentrations were measured in one system of units while drug doses were administered in another. ${ }^{6}$; A change to molar units for drugs and toxins would cause little inconvenience to clinical biochemists but it would have enormous repercussions on the medical and nursing professions, medical education, clinical pharmacology and toxicology, pharmacy, and the pharmaceutical industry. It would be very expensive and the confusion which would occur during and for long after the changeover is unimaginable. Such a drastic and painful move could be justified only by an overwhelming advantage of molar over mass units.

Attention has already been drawn to the hazards in clinical toxicology caused by the premature use of molar units by some laboratories, ${ }^{68}$ and the pros and cons of the two different systems of units have been debated at some length. ${ }^{1-36-11}$ Despite the superficially persuasive arguments put forward by clinical biochemists, it is obvious that there would be no practical clinical advantage if molar units were introduced for drugs and toxins. The outstanding disadvantage of molar units is that the molecular weight of the compound must be known to give any physical reality to the value in question. It would be impossible to cope in this way with the enormous range of drugs and toxins of differing molecular weight which are encountered in clinical practice.
Everyone agrees that standardisation of units for drug measurement is necessary, but it is presumptuous, if not arrogant, of clinical biochemists to attempt to force a change to molar units without wide consultation and the majority agreement of all those who are likely to be affected. It is proposed to prepare a definitive document reflecting the official position of clinical, industrial, and other specialty interests in this matter. In the mean time I hope that common sense will prevail and that clinical biochemists will appreciate the reasons for the resentment and depth of opposition to their proposals.

L F PRESCOTT

University Department of Clinical Pharmacology
and Regional Poisoning Treatment Centre,

and Regional Poyal Infirmary

Edinburgh EH3 9 YW

1 Stewart MJ, Watson ID. Standard units for expressing drug concentrations in biological fluids. $\mathrm{Br} \mathrm{f}$ Clin Pharmacol 1983;16:3-7.

2 Ratcliffe JG, Worth HGJ. Recommended units for reporting drug concentrations in biological fluids. Lancet 1986; :202-3.

3 Watson ID, Stewart MJ Morgan HG Units for drug concentra tions in biological fluids. Lancet 1986;: $741-2$.

4 Baron DN. Use of molar units for drugs and toxins? $\mathrm{Br}$ Med $\mathrm{F}$ 1986;293:2-3.

5 Lundberg GD, Iverson C, Radulescu G. Now read this: SI units are here. JAMA 1986;255:2329-30.

6 Prescott LF, Stewart MJ, Proudfoot AT. SI, moles and drugs. $\mathrm{Br}$ Med F 1978;ii: 1620.

7 Begg EJ. Units for drug concentrations in biological fluids. Lancet 1986; i:505.

8 Crome P, Widdop B, Volans G, Goulding R. SI, moles, and drugs. Br.Med f 1978; ;i: 1277

9 Simpson D. Units for reporting the results of toxicological measurements. Ann Clin Biochem 1980;17:328-31.

10 Uges DRA. Units for therapeutic drug monitoring toxicology. Lancet 1986;i:979-80.

11 Brodie MJ, Murray T, Hallworth MJ. Units for drug concentrations in biological fluids. Lancet 1986; ;:505.

Diabetic renal disease: differences between Asian and white patients

SIR,-D A Samanta and colleagues recorded a significantly higher prevalence of proteinuria in Asian (Indian) diabetics than in white diabetics, which they believed to be due to microvascular disease (9 August, p 367). We have reported a high prevalence $(18 \%)$ of microvascular complications in 85 South African Indian patients with noninsulin dependent diabetes in the young. ${ }^{1-4}$

The $18 \%$ prevalence of microvascular complications contrasts with the findings of most workers reporting on non-insulin dependent diabetes in young white patients, who have highlighted the rarity of vascular complications in their patients. ${ }^{48}$ However, Fajans has reported a similar frequency of microvascular complications in such patients. ${ }^{9}$ While most patients with microvascular complications in Fajans's series (16 of 17) had had diabetes for over 15 years, in accordance with the data of Dr Samanta and others, half of our South African Indian patients with microvascular complications had had diabetes for less than 10 years. Thus in addition to Indian diabetics having a much higher prevalence of microvascular complications than whites they also seem to have a shorter duration of diabetes.

\section{MRC Preclinical Diagnostic \\ Chemistry Research Unit,}

Department of Chemical Pathology,

University of Natal Medical School,

Durban, RSA

1 Jialal I, Joubert SM, Asmal AC, Jenkins N. The insulin and glucose response to an oral glucose load in non-insulindependent diabetes in the young. S Afr Med f 1982;61:35

2 Jialal I, Welsh N, Joubert SM, Rajput M. Vascular complication in non-insulin-dependent diabetes in the young. S Afr Med $\mathcal{F}$ 1982;62:155-7.

3 Jialal I, Rajput MC, Asmal AC, Joubert SM. Nephropathy in Indian patients with non-insulin-dependent diabetes in the young. Diabetes Care 1984;7:587-9.
4 Jialal I, Joubert SM. The biochemical profile in Indian patients with non-insulin-dependent diabetes in the young with retinopathy. Diabete et Metabolisme 1985;11:262-5.

5 Tattersall RB. Mild familial diabetes with dominant inheritance. Quart f Med 1974;43:339-57.

6 Barbosa J, Ramsay R, Goetz F. Plasma glucose, insulin, glucagon and growth hormone in kindreds with maturity onset type
hyperglycaemia in young people. Ann Intern Med 1978; 88:595-601.

7 Tulloch J, Adamson D. Dominant inheritance of diabetes mellitus. I R Coll Physicians Lond 1976;11:86-90.

8 Kobberling J, Bengsch N, Bruggeboes B, Schwarcka H, Tillil H, Weber $M$. The chlorpropamide alcohol flush: lack of specificity for familial non-insulin-dependent diabetes. Diabetologia 1980;19:3646.

9 Fajans SS. Heterogeneity between various families with noninsulin-dependent diabetes of the MODY type. In: Kobberling J, Tattersall R, eds. Proceedings of the Serono Symposium. The genetics of diabetes mellitus No 47. New York: Academic Press, 1982.

SIR,-Further details are required before the preliminary results of $\mathrm{Dr}$ A Samanta and his colleagues can be accepted.

Surely it is time for a more restricted definition of ethnic group than "Asian." They might perhaps have specified "of Gujerati origin" in their title. Although many of us have used the term "Asian" as a flag of convenience, ${ }^{1}$ knowledge has progressed. Environmental factors affecting culturally diverse groups of British citizens originating from the Indian subcontinent cannot be assumed to be the same-let alone assuming that such groups share a similar gene pool. ${ }^{2}$ Standardisation of terms is urgently needed.

As with all clinic studies, sampling biases may be large. The authors mention potential referral bias but what does "consecutive" mean for Asian and white attenders of at least one year? Was every attender from date $A$ to date $B$ included? What proportion of the total white attenders at the Leicester clinic do the 368 whites represent? Were they stratified by sex, accounting for the nearly even sex balance between Asians and whites?

By chance one clinic in 20 will find a "significant" $(p<0.05)$ excess (or deficit) in some variable-that may be " $p<0.001$ " in that clinic. Confidence intervals should have been given. The $99 \%$ confidence interval $(2 \cdot 58 \mathrm{xSE})$ for the proportion of all Asians with proteinuria $(53 / 370=14 \%)$ is $9 \cdot 4$ to $18 \cdot 6 \%$ and for all whites $(23 / 368) 2 \cdot 8$ to $9 \cdot 2 \%$-for example, distributions that are only just apart. For the sexes separately $99 \%$ confidence intervals overlap with those for whites.

A further problem is that only $37 \cdot 1 \%(135 / 370)$ of Asians were treated with insulin compared with $70 \cdot 1 \%(258 / 368)$ of whites. This is high for a typical sample of whites of that age (mean (SD12)). Is it possible that the proteinuria was partly due to toxicity from the oral agents-a spectre that has been raised before ? $^{3}$

The authors suggest that their data need confirmation from epidemiological work. We currently have a population sampling study underway among three ethnic groups (one being Gujerati) in Brent and Harrow. Unfortunately, the sample sizes and time required are too great to compare the incidence of diabetic proteinuria, which is what is needed. However, perhaps those of us with research interests in the diabetic problems of ethnic groups in the UK should discuss methods of standardising our data bases. Their combined size, properly managed, would allow pressing public health topics ${ }^{47}$ in this subject to be analysed adequately and developed for clinical trials and other preventive work.

Diabetic and Epidemiology Units,

Northwick Park Hospital, Harrow,

Middx HAl 3UJ

1 Cruickshank JK, Beevers DG, Osbourne V, Selby S. Heart attack, stroke, diabetes and hypertension among Asians and West Indians in Birmingham, England. Br Med $\mathcal{F}$ 1980;281: 1108-9. 